\title{
Effect of septal lesions, required response, and shock on the acquisition of a two-way conditioned avoidance response in rats
}

\author{
DAVID A. DALBY and DUANE E. SHUTTLESWORTH \\ University of North Carolina at Greensboro, Greensboro, North Carolina 27412
}

\begin{abstract}
Normal albino rats and rats with septal lesions were trained to a criterion of $9 / 10$ avoidance responses in a two-way conditioned avoidance response (CAR) task. The animals were required to run through a doorway or climb over a hurdle, and were motivated by continuous shock or intermittent shock. The subjects showed facilitated acquisition of the CAR if they sustained a septal lesion and/or were trained in the hurdle condition. The type of shock had no effect on learning. Lesioned subjects made more intertrial responses than normals. It is suggested that rats with septal lesions learn faster because they are more fearful, and that response requirement is an important variable in shuttlebox avoidance conditioning.
\end{abstract}

Since the early study by King (1958), there has been the consistent finding that rats sustaining lesions of the septal forebrain acquire a two-way conditioned avoidance response (CAR) faster than do normal animals. Dalby (1970), however, reported that rats with septal lesions were retarded in learning a twoway CAR. Two unique factors in Dalby's study were that the two compartments of the apparatus were separated by a high hurdle and that intermittent shock was used to motivate the animals. Either one of these two factors, or perhaps an interaction of them, might have served to produce slower learning by the animals with septal lesions.

The present experiment was conducted to test the replicability and generality of Dalby's results, and to investigate separately the effects of employing a doorway vs. a hurdle and continuous shock vs. intermittent shock in a shuttlebox on the behavior of normal and septally lesioned rats.

\section{METHOD}

\section{Subjects}

The subjects were 160 male albino rats weighing $250-300 \mathrm{~g}$ at the beginning of the experiment. The rats were assigned randomly to a control group or to an experimental group. The control group consisted of normal rats, and the experimental group consisted of rats sustaining bilateral lesions of the septal region of the forebrain. All animals were housed in individual cages and given constant access to food and water.

This research was supported by Grant $\mathbf{4 1 3}$ from the University of North Carolina at Greensboro Research Council to David A. Dalby. D. A. Dalby's present address is Department of Psychology, Phoenix College, $1202 \mathrm{~W}$. Thomas Road, Phoenix, Arizona 85013. Requests for reprints should be sent to Duane E. Shuttlesworth, Psychosocial Sciences, Capitol Campus, Pennsylvania State University, Middletown, Pennsylvania 17057.

\section{Experimental Design}

All animals were trained in a two-way CAR task according to a 2 by 2 by 2 factorial design with three main factors of lesion, habit, and shock. The two levels of lesion were none vs. septal, the two levels of habit were doorway vs. hurdle, and the two levels of shock were continuous vs. intermittent. There were eight different groups, with 20 subjects in each group.

\section{Surgery}

Surgery was performed under Equi-Thesin anesthesia injected intraperitoneally. The septal lesions were produced by intracerebral insertion bilaterally of an electrode that was insulated except for $0.5 \mathrm{~mm}$ at the tip. A direct current of $2.0 \mathrm{~mA}$ was passed for $20 \mathrm{sec}$ through this electrode, with an anal electrode completing the circuit. The stereotaxic coordinates, as computed from the atlas by de Groot (1959) were anterior-posterior +8.0, lateral \pm 0.5 , and dorsal-ventral +1.0 . Following surgery, all operated animals were allowed a 2-day recovery period before the start of training.

\section{Apparatus}

The apparatus was a two-way shuttlebox similar to one previously described by Meyer, Johnson, and Vaughn (1970). For half of the animals, the two compartments were separated by a $4 \times 4$ in. doorway, and for the remaining half, the compartments were separated by a 4-in.-high hurdle. The grid and top of the hurdle could be electrified. A door buzzer located 7 in. above the top-center of the apparatus provided an auditory stimulus of 82-dB SPL above a white-noise background of $67 \mathrm{~dB}$ SPL as measured at the front-center of the box with a General Radio 1551-C sound-level meter adjusted to a flat weighting $(20 \mathrm{kHz})$.

\section{Procedure}

The pretraining and training procedures were those described by Dalby (1970). On Day 1, the rat was placed in the apparatus and allowed to explore for $5 \mathrm{~min}$. The animal was then given 25 habituation trials to a 5-sec CS (onset of the buzzer) followed by an intertrial interval (ITI) of $30 \mathrm{sec}$.

On Day 2, avoidance training was begun, and avoidance trials were presented every $30 \mathrm{sec}$. The required response was movement of the rat from one compartment into the other compartment during presentation of the CS. The onset of the buzzer was followed by shock after $5 \mathrm{sec}$ unless the subject made the required response within this interval. If the rat did not cross during the 
interval, continuous shock (.6-.8 mA) was applied or brief intermittent shock (.6-.8 mA) was administered at the rate of 1 shock/ $2 \mathrm{sec}$. When either an escape or avoidance response was made, the CS and shock were terminated simultaneously. The CS-shock sequence was started and terminated by manual switches operated by the experimenter. The frequency of intermittent shock was controlled automatically. The animals were not shocked for crossings during the $30-\mathrm{sec}$ ITI. Training was conducted for 25 trials/day until the rat made nine avoidance responses out of any 10 successive trials.

\section{Histology}

After reaching the $9 / 10$ criterion, operated animals were given an overdose of Equi-Thesin anesthesia and perfused intracardially with $.9 \%$ saline followed by $10 \%$ Formalin. The brains were removed from the skull, placed in Formalin for several days, embedded in celloidin, and serially sectioned at 30 micra. Every tenth section through the septum was saved, mounted, and stained with cresyl violet. The sections were then examined microscopically.

Figure 1 illustrates the location and extent of the septal lesions. The lesions were generally symmetrical, with bilateral damage starting just posterior to the genu of the corpus callosum, and extending dorsally to the corpus callosum, ventrally to the level of the anterior commissure, laterally to the caudate nucleus, and posteriorly into the columns of the fornix. The only atypical damage was bilateral involvement of the anterior thalamus in 15 brains. Slight injury to the corpus callosum or cingulate cortex was noted in 10 animals, and damage to the caudate nucleus in 6 subjects. On the first postoperative day of training, $81 \%$ of the operated animals showed hyperreactivity to handling.
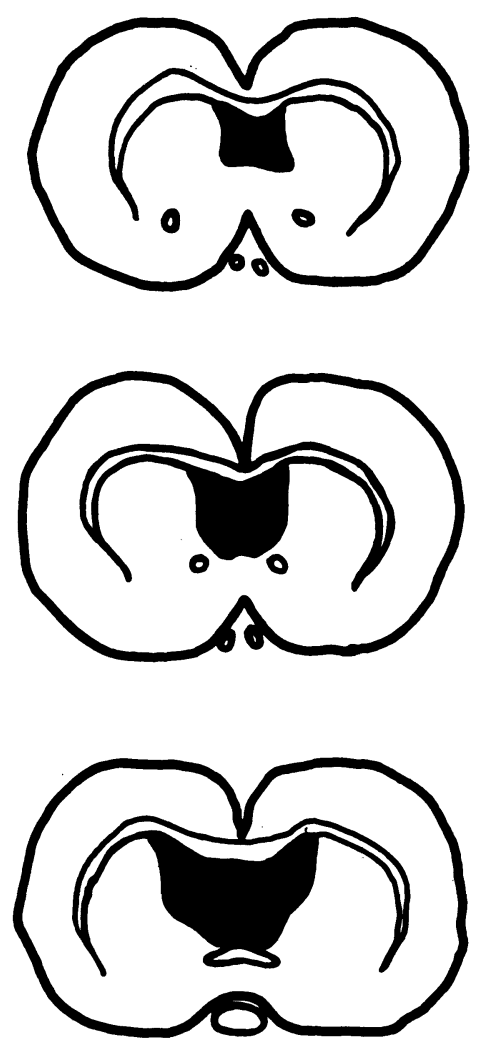

Figure 1. Drawings illustrating the locus and extent of septal lesions.

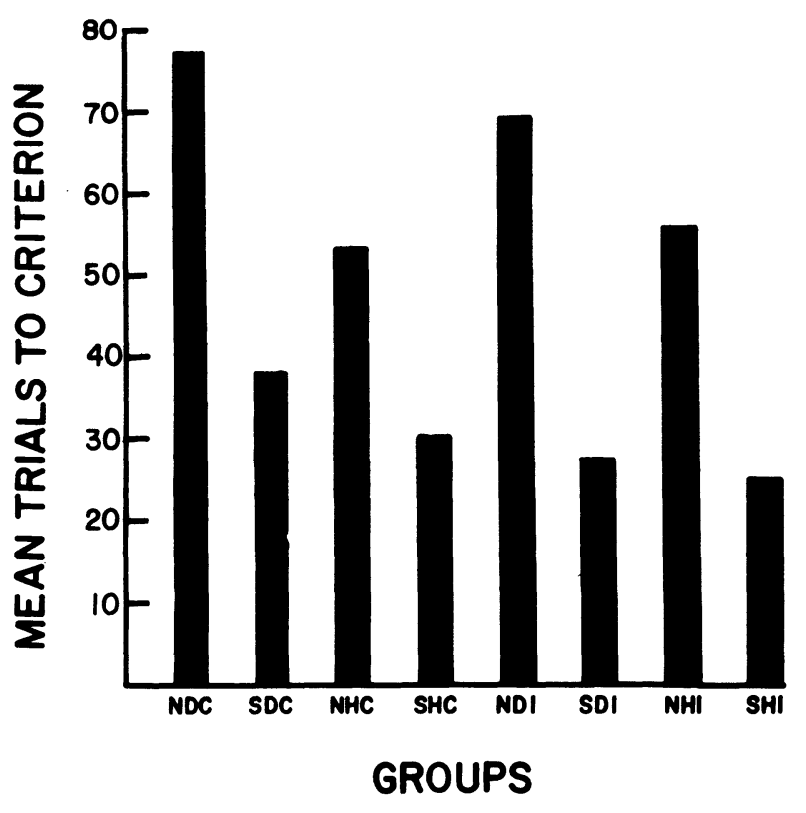

Figure 2. Mean numbers of trials to reach the $9 / 10$ criterion for all groups $(n=20)$. N, normal; $S$, septal lesion, $D$, doorway habit; H, hurdle habit; $C$, continuous shock; and I, intermittent shock. For example, Group NHI would be normal animals trained on the hurdle task under intermittent shock.

\section{RESULTS}

Figure 2 presents the mean numbers of trials required by all groups to reach the $9 / 10$ criterion.

There are two outstanding characteristics of these results. First, all septal groups reached the learning criterion faster than their respective normal control groups. Secondly, all groups trained in the hurdle situation learned faster than their equivalent groups trained in the doorway condition. An analysis of variance conducted on the trials required to reach the 9/10 criterion revealed significant differences among the eight groups for the lesion factor $(F=58.83$, $\mathrm{df}=1 / 152, \mathrm{p}<.001)$ and for the habit factor $(\mathrm{F}=$ 7.54 , df $=1 / 152, \mathrm{p}<.01$ ), but no significant differences for the shock factor and no significant interactions. Thus, animals with septal lesions were facilitated in learning the CAR as compared to normal rats, regardless of the response required or the type of shock. The response requirement was important because significantly fewer trials were necessary to learn when the animals were forced to climb over a hurdle $(\bar{X}=41.4)$ than when they had to shuttle through a doorway $(\bar{X}=53.4)$. Although the shock factor was not significant, fewer trials were required to reach criterion by subjects trained under intermittent shock $(\overline{\mathrm{X}}=44.6)$ than by animals trained under continuous shock $(\overline{\mathrm{X}}=50.2)$. 
Since training procedures for normal and septal rats trained on the hurdle task under intermittent shock conditions were similar to those used by Dalby (1970), the difference between the mean scores was tested by the Tukey a procedure (Winer, 1962). Septal animals $(\overline{\mathrm{X}}=25.4)$ learned faster than did normal rats $(\overline{\mathrm{X}}=55.9)$, and this difference was significant $(\mathrm{p}<.05)$.

An analysis of variance conducted on the proportion of intertrial responses (ITRs) per trial for individuals of the eight groups indicated a significant difference among the groups for the main effect of lesion $(F=8.96$, df $=1 / 152, p<.005)$. Animals with septal lesions made more ITRs/trial $(\overline{\mathrm{X}}=.3)$ than did normal rats $(\overline{\mathrm{X}}=.1)$. There were no significant interactions.

Since septal animals learned faster and also made more ITRs, correlation coefficients were computed between the trials to the $9 / 10$ criterion and the ITRs/ trial for all rats, for normal rats alone, and for septal animals alone. In all three instances, a small but significant negative correlation was found between trials to criterion and frequency of ITRs, i.e., faster learning was correlated with more ITRs. However, the association between rate of learning and ITRs was not high, because the amount of variance in the trials to criterion accounted for only $5 \%-9 \%$ of the variance in the ITRs.

\section{DISCUSSION}

The results confirm the well-documented finding that rats with septal lesions show facilitated learning in two-way CAR tasks (Green \& Schwartzbaum, 1968; Kenyon \& Krieckhaus, 1965a, 1965b; King, 1958; Kriekhaus, Simmons, Thomas, \& Kenyon, 1964; Meyer et al., 1970; Novick \& Phil, 1969; Schwartzbaum, Green, Beatty, \& Thompson, 1967; Trafton, 1967; Van Hosen, MacDougall, \& Mitchell, 1969). The results of Dalby's (1970) study were not supported, however, since septal animals trained in the hurdle task under intermittent shock acquired the CAR faster than their normal counterparts. The addition of a hurdle and/or intermittent shock to a typical shuttlebox does not retard the acquisition of a two-way CAR by rats with septal lesions as Dalby suggested, but, as shown by the present results, facilitates learning. Dalby's discrepant results were most likely a function of internal cues specific to the apparatus he employed. This conclusion is supported by comparing learning rates for normal and septal groups in Dalby's study with those of similarly trained groups in the present experiment. The normal group in Dalby's study learned significantly faster than the present normal groups (33.0 vs. $56.0 ; F=11.07$, $\mathrm{df}=1 / 38, \mathrm{p}<.005)$, while conversely, the septal group learned significantly more slowly than the present septal group (48.0 vs. $25.4 ; F=15.51$, df $=1 / 38, p<.001$ ).

The presence of a hurdle lead to faster acquisition of the CAR. Two possible explanations may be offered to account for this result. First, the hurdle effectively divides the apparatus into two distinct compartments (Dalby, 1970) defining the response by allowing the subject to readily discriminate shock and no-shock areas of the box. That is, typical shuttleboxes, consisting of two compartments with a door or a low $1-1 \frac{1}{2}$ in. hurdle between them, have not presented a situation that was readily discriminable by rats from a single box (Dalby, 1970). A second possibility is that the hurdle required a response which was higher up on the rat's response hierarchy than the typical doorway (shuttle) response. It may be that the hurdle response is more compatible with the animal's species-specific defense reaction to flee (Bolles, 1970) in an avoidance situation than is the shuttle response. This could lead to faster acquisition of the required response.

Since the type of shock did not influence the learning of a two-way CAR, the results of the present investigation do not support the findings of Moyer and Chapman (1966). The reason for this may well be found in the different levels of shock intensity employed in the experiments. Moyer and Chapman used a relatively high shock intensity $(1.5 \mathrm{~mA})$ while, in the present experiment, shock intensity varied between .6 and $.8 \mathrm{~mA}$. The high-intensity shock used by Moyer and Chapman may have induced an inordinate amount of freezing (response suppression) in the continuous shock group but not in the intermittent shock group. In the present study, when lower intensity shock was used, no difference between intermittent and continuous shock is found. It can be suggested that the facilitated learning with intermittent shock found by previous workers who employed discriminated operant avoidance tasks (Biederman, 1967, 1969; Biederman, D'Amato, \& Keller, 1964; D'Amato, Keller, \& Biederman, 1968; D'Amato, Keller, \& DiCara, 1964; Hess \& Shafer, 1968a, 1968b; Shafer \& Hess, 1969) does not generalize to shuttlebox avoidance habits as Moyer and Chapman have suggested, at least not when low levels of shock are used.

Dalby (1970) suggested that rats with septal lesions may be more fearful than normal subjects, and that increased fear is the main factor which accounts for the behavior of such preparations in a shuttlebox avoidance task. Septally lesioned rats are hyperreactive to tactile-shock stimulation and tend to make more shuttle responses during the ITI than do normal animals. Responding during the ITI might also indicate increased fear of being shocked, especially in tasks where movement from one area of the apparatus is negatively reinforced by the avoidance of shock. 
Intertrial responses could be a learned response to fear. On the other hand, increased ITRs could also result from a decreased fear of shock (Kenyon \& Krieckhaus, 1965b). An equally plausible alternative is disinhibition. That is, increased ITRs could result from the loss of a neurologic response mechanism underlying the inhibition of voluntary movement in septally lesioned rats.

It can be suggested that faster learning results from the tendency of septal animals to make more ITRs. However, since the amount of variance accounted for by the correlation between learning and ITRs was small, it is suggested that increased responding during the ITI was not the major factor that contributed to faster acquisition of the CAR. More likely, the ITRs were simply a manifestation of increased or decreased fearfulness in rats with septal lesions, or the result of the loss of a response suppression mechanism underlying the inhibition of voluntary movement.

\section{REFERENCES}

Biederman, G. B. Discriminated avoidance conditioning as a function of duration of intertrial interval and type of shock. Psychonomic Science, 1967, 9, 155-156.

Biederman, G. B. The role of discontinuous US in discriminated avoidance learning. Psychonomic Science, 1969, 14, 237-238.

Biederman, G. B., D'Amato, M. R., \& Keller, D. M. Facilitation of discriminated avoidance learning by dissociation of CS and manipulation. Psychonomic Science, 1964, 1, 229-230.

Bolles, R. C. Species-specific defense reactions and avoidance learning. Psychological Review, 1970, 77, 32-48.

DALBY, D. A. Effect of septal lesions on the acquisition of two types of active-avoidance behavior in rats. Journal of Comparative and Physiological Psychology, 1970, 73, 278-283.

D'Amato, M. R., \& Fazzaro, J. Discriminated lever-press avoidance learning as a function of type and intensity of shock. Journal of Comparative and Physiological Psychology, 1966, 61, 313-315.

D'Amato, M. R., Keller, D., \& Biederman, G. Discriminated avoidance learning as a function of parameters of discontinuous shock. Journal of Experimental Psychology, 1968, 77, 543-547.

D'Amato, M. R., Kellar, D., \& DiCara, L. Facilitation of discriminated avoidance learning by discontinuous shock. Journal of Comparative and Physiological Psychology, 1964, 58, 344-349.

DE GROOT, J. The rat forebrain in stereotaxic coordinates. Verhandelingen der Koniklijke Nederlandsche Akademic van Wetenschappen Natuurkunde, 1959, 52, 1-40.
Green, R. H., \& Schwartzbaum, J. S. Effects of unilateral septal lesions on avoidance behavior, discrimination reversal, and hippocampal EEG. Journal of Comparative and Physiological Psychology, 1968, 65, 388-396.

Hess, J. H., \& Shafer, J. N. Discontinuous shock and generalization to preshock period in discriminated avoidance learning. Psychonomic Science, 1968, 10, 175-176. (a)

Hess, J. H., \& Shafer, J. N. Escape response distribution and discriminated avoidance of discontinuous shock. Psychonomic Science, 1968, 11, 255-256. (b)

KenYon, J., \& Krieckraus, E. E. Enhanced avoidance behavior following septal lesions in the rat as a function of lesion size and spontaneous activity. Journal of Comparative and Physio: logical Psychology, 1965, 59, 466-469. (a)

Kenyon, J., \& Krieckhaus, E. E. Decrements in one-way avoidance learning following septal lesions in rats. Psychonomic Science, 1965, 3, 113-114. (b)

KING, F. A. Effects of septal and amygdaloid lesions on emotional behavior and conditioned avoidance responses in the rat. Journal of Nervous and Mental Diseases, 1958, 126, 57-63.

Krieckhaus, E. E., Simmons, H. J., Thomas, G. J., \& Kenyon, J. Septal lesions enhance shock avoidance behavior in the rat. Experimental Neurology, 1964, 9, 107-113.

MeYer, P. M., Johnson, D. A., \& VAughn, D. W. The consequences of septal and neocortical ablations upon learning a two-way conditioned avoidance response. Brain Research, 1970, 22, 113-120.

Moyer, K. E., \& Chapman, J. A. Effect of continuous vs. discontinuous shock on shuttle box avoidance in the rat. Psychonomic Science, 1966, 4, 197-198.

Novick, I., \& PHIL, R. Effect of amphetamine on the septal syndrome in rats. Journal of Comparative and Physiological Psychology, 1969, 68, 220-225.

Schwartzbaum, J. S., Green, R. H., Beatty, W. W., \& Thompson, J. B. Acquisition of avoidance behavior following septal lesions in the rat. Journal of Comparative and Physiological Psychology, 1967, 63, 191-197.

ShAFER, J. N., \& Hess, J. H. Discrimination avoidance learning with alternate discontinuous and continuous US escape trials. Psychonomic Science, 1969, 14, 237-238.

Trafton, C. L. Effects of lesions in the septal area and cingulate cortical areas on conditioned suppression of activity and avoidance behavior in rats. Journal of Comparative and Physiological Psychology, 1967, 63, 191-197.

Van Hosen, G. W., MacDougall, J. M., \& Mitchell, J. C. Anatomical specificity of septal projections in active and passive avoidance behavior in rats. Journal of Comparative and Physiological Psychology, 1969, 68, 80-89.

WINER, B. S. Statistical principles in experimental design. New York: McGraw-Hill, 1962.

(Received for publication September 8, 1977; revision accepted November $21,1977$. 